\title{
Social Work and Neurosciences: Speeches and Theoretical Contributions
}

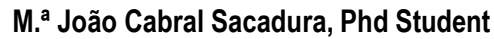 \\ Catholic University of Portugal and University of Coimbra, Portugal \\ Helena Neves Almeida, Phd \\ Professor and Researcher. Faculty of Psychology and Education Sciences \\ University of Coimbra, Portugal
}

\begin{abstract}
The concept of "neuroscience" sometimes referred to as "the last frontier of biology" (Squire et al., 2008, p. 3) was introduced in the mid-1960s and is now recognized as a multidisciplinary field that analyzes the nervous system to understand the biological basis of human behavior. The ongoing developments and the arising production regarding the deepening of the structure, functions and functioning of the brain and its interaction with the environment enabled the identification of key elements reaching an unprecedented level of knowledge in the history of humankind. The multidisciplinary scientific approach, including non-clinical areas such as music, philosophy, education, mathematics, economics and physics, has also contributed to its further deepening. In the light of this scenario of interdependencies and disciplinary alliances, the discipline of the social and human sciences - social work - whose subject is conceived "from and for the practice" (Parton, 1996) in the day-to-day work with challenging social problems of various types and with different publics. Therefore, the present article aims to analyze what has been done to date since 2001, namely the input and contributions of authors and researchers in the field as well as to understand the input of neuroscience developments in their education and research. Also worth mentioning is the identification and relevance of the links between these domains which have contributed to the enrichment of the profession.
\end{abstract}

Keywords: social work, neuroscience, education, social intervention

\section{Introduction}

Neurosciences reached the peak of their development during the so-called "decade of the brain" (1990-1999) and, for the last 17 years, social work has been following the discussion and contemporary thought on the input produced by neuroscience, seeking to build bridges between both areas. It therefore presents itself as one of many scientific disciplines which recognized the importance of incorporating neuroscientific contributions into its own field of knowledge, whilst underlining the nature of social work and the need to understand people's behavior within the context of their living environment.

The theoretical approaches of "person in situation" and "person in environment" are the cornerstones of the profession which sustain a comprehensive understanding of the support given to the individual and its system:

'The 'person in situation' and 'person in environment' has long since been cornerstone of the profession. Clients need to be supported and changes that occur in an individual need to be supported within the environment where the client lives and thrives. There is no magic cure or pill to cure anything without a holistic understanding of the person's support and environmental system" (Dziegielewski, 2010, p. xiii).

In the light of this perspective and by means of the present literature review, our goal was to identify theoretical approaches to and thoughts on the relationship between social work and neurosciences which highlight its significance in training, professional practice and area of research. 
Sayer (2014) points outthat this body of research in the field ofneurosciences is underpinned by contemporary and historical perspectives on social work.

The aim of systematizing the literature review was to gather several approaches and arguments which incorporated the most relevant and reliable contributions on the subject under research. To that end, we

accessed the Portuguese Catholic University webpage as well as that of the Libraries of the University of Coimbra in order to collect the existing scientific databases available online. In addition, we resorted to the Google search engine and the b-on (Online Knowledge Library). During the execution of this task, we sought to confer greater relevance to scientific articles and reference books specifically related to the field, within a time span of approximately five years. It was not always possible to comply with this criterion given the need to gather complementary information so as to define the framework of the subject matter. Consequently, the literature review covers the time period between 2001 and 2017. Hence the use of keywords and combinations of keywords as guiding points in order to detect relevant articles about the relationship of the topics in question: social work and neuroscience.

The b-on presented 462,879 results and, from this starting point, we narrowed the theme on the basis of certain exclusion criteria, namely documents with no direct relation to the subject matter. This collection also resulted in the identification of works by authors of reference, which, in turn, enabled the narrowing of the collection itself.

- The importance of neuroscience in social work - training, research and intervention

There are countless examples from 2001 onwards which demonstrate that many authors and researchers have focused their studies and analyses on the importance played by this relationship in social workers' academic training, intervention practices and research.

According to Egan (2001), thanks to these new findings, the discipline of social work has access to vital contributions to the understanding of human behavior and social environment. In the field of neuroscience, the study continues and never could one conceive of the functioning of the human brain, as well as its disorders and importance to our mental or physical health, as being disconnected from the existence of people within a society (Sena, 2016, p. XI).

The reference literature focusing on the relationship between social work and neuroscience includes authors such as Shapiro (2010), Farmer (2013), Egan, Combs-Orme, \& Neely-Barnes (2011), Miehls (2011), Matto (2013), Montgomery (2013), Sayre (2014) and Maynard, Boutwell, \& Vaughn (2015) who advocate the need to integrate neuroscientific developments into the way social workers view and understand the complexity of the world in order to guide and improve their interventions (table 1).

\section{Table 1 - Contributions of neurosciences to social work practices}

\begin{tabular}{|c|c|c|}
\hline Author/Year & Work & Contributions \\
\hline $\begin{array}{l}\text { Shapiro, J.R., Applegate, } \\
\text { J.S. (2005) }\end{array}$ & $\begin{array}{l}\text { Neurobiology for Clinical Social Work. } \\
\text { Theory and Practice }\end{array}$ & $\begin{array}{l}\text { New research findings on the neurobiology of attachment } \\
\text { Infant mental health } \\
\text { Neurobiology of memory }\end{array}$ \\
\hline Farmer, R.L. (2009) & $\begin{array}{l}\text { Neuroscience and Social Work Practice: } \\
\text { the Missing Link }\end{array}$ & $\begin{array}{l}\text { Reasons to incorporate emerging research in social work } \\
\text { training and practice } \\
\text { Link to social neuroscience Transactional Model } \\
\text { Framework } \\
\text { Advocating (e.g. child neglect), fundamental } \\
\text { understandings, } \\
\text { policy-relevant understandings, client practice-level } \\
\text { understandings Neurobiology of abuse/addiction }\end{array}$ \\
\hline Montgomery, A. (2013) & $\begin{array}{l}\text { Toward the Integration of Neuroscience } \\
\text { and Clinical Social Work }\end{array}$ & $\begin{array}{l}\text { Integration into psychodynamic social work } \\
\text { Relevance for social workers school curricula, regarding } \\
\text { policy-related issues, human development and social } \\
\text { environment, social justice, diversity and its potential to } \\
\text { other approaches related to various human problems }\end{array}$ \\
\hline
\end{tabular}




\begin{tabular}{|l|l|l|}
\hline $\begin{array}{l}\text { Matto, H.C., Strolin-Neuroscience for Social Work } \\
\text { Goltzman, J., Ballan, M.S. } \\
(2014)\end{array}$ & $\begin{array}{l}\text { Importance to the design, development and expansion of } \\
\text { therapeutic interventions, social programs and policies for } \\
\text { working with the most vulnerable populations } \\
\text { Practice intersections of neuroscience development and } \\
\text { social work, child welfare and education, health and } \\
\text { mental health practice and criminal justice }\end{array}$ \\
\hline Sayre, M., Walker, R. (2014) & $\begin{array}{l}\text { Evolutionary Theory and Neuroscience: An } \\
\text { Explanatory Theory for Social Work }\end{array}$ & $\begin{array}{l}\text { Suggestion to incorporate the Evolutionary Theory, a guide } \\
\text { to social work practice }\end{array}$ \\
\hline
\end{tabular}

The relevance of neurosciences in social work training, practice and research is based on the following arguments:

- By increasing our understanding of how the brain works, neuroscience provides explanations to many of the personal and social problems encountered by social workers (Farmer, 2009).

"(...) more extensive neuroscientific and other science-based explanations can help social workers in explaining the emotional, psychological, social, and behavioral difficulties that we encounter" (Farmer, 2009, p. 82).

- These contributions enhance our knowledge and understanding of the role of the brain in human development and behavior (Egan, Combs-Orme, \& Neely-Barnes, 2011; DiPietro, 2000; Negash

\section{\& Petersen, 2006; Weatherston, 2001).}

"Understanding how the brain develops in infancy and connecting ontogeny with functioning helps social workers understand the tremendous importance of infancy for brain development and future functioning and achievement. Many (if not most) of the problems in which social workers intervene arguably have roots in this period of life (Combs-Orme, Wilson, Cain, Page, \& Kirby, 2003).

Enhanced understanding of the importance of infancy through integration of neuroscience content should provide social workers with knowledge to influence social policy and service design and delivery (Egan, Neely-Barnes, \& Combs-Orme, 2011)" (Combs-Orme et al., 2015, p. 645).

- Social work can take into account the biological components of the psychosocial perspective in order to inform practices (Shapiro, 2010; Farmer, 2015) and strengthen the advocacy function in multiple areas (Shapiro, 2010; Farmer, 2009, 2013; Egan, Combs-Orme, \& Neely-Barnes, 2011).

"One expanding area of inquiry is the neuroscience related to the effects of social disadvantage. Social and cognitive scientists have long documented a range of behavioral and cognitive deficits that are found more commonly in people from deprived circumstances" (Wax, 2017, p. 2).

- Given the interdisciplinary nature of social work, social workers are well positioned to contribute with and integrate their social and behavioral research, while also translating those research findings into practice and the development of new interventions (Egan, Combs-Orme, \& Neely-Barnes, 2011).

"Given the social work's interdisciplinary nature, social workers are well positioned to contribute to the integration of social and behavioral research and translate these research findings into practice (McCutcheon, 2006; National Association of Social Workers (NASW), 2003). Indeed, biosocial research is essential for a deeper understanding of the problems with which social workers are concerned and can improve our understanding of the etiology and course of conditions to inform more accurate assessment strategies" (Maynard, B., Boutwell, B., \& Vaughn, M. , 2015, p.2).

- The knowledge of neuroscience promotes an interdisciplinary practice through the use of a common language, as in situations related to psychopathology, drug abuse and cognitive aspects

of aging; explanations about the functioning of the brain and psychopathology may offer new evidence or discredit existing ones (Egan, Combs-Orme, \& Neely-Barnes, 2011).

Egan, Combs-Orme and Neely-Barnes (2011) argue that if social workers are knowledgeable about brain and nervous system interactions as well as the relevant psychosocial elements, and use the language employed by their peers in 
multidisciplinary teams, their way of communicating will become more effective, thus enhancing the transdisciplinary environment of the professional practice.

- Practices are the focus of social work.

"The knowledge gained through biosocial research can inform and enhance interventions by allowing us to better understand mechanisms through which interventions work and more effectively and efficiently target biosocial variables and interactions that predict and moderate treatment response" (Maynard, Boutwell \&, Vaughn, 2015, p. 2).

However, Maynard, Boutwell and Vaughn (2015), Garland and Howard (2009) consider that, even though social work highlights the biopsychosocial perspective in the understanding of human behavior and in the relevance of contributions made by biosocial research for the practice of social workers, it has had a rather unclear impact on practices.

According to Farmer (2009), the integration of neuroscience into the perspective of biopsychosocial human behavior prepares social workers for a transdisciplinary environment which can promote improved care continuity for clients and families, thus fostering a better assistance which takes into account brain- related conditions and diseases. Moreover, it equips them to practice advocacy, particularly with regard to intervention in early intervention programs, drug abuse prevention and other treatments as well as to work interdisciplinarily.

The author states that its potential, regarding social work intervention, comprises four main areas: it increases our knowledge about the role of the brain in human development and its impact on behavior (since the formation of the brain before birth until its functioning in adulthood); it encourages new insights for theories and models of social intervention; it provides scientific support to social work with an evidence- based practice and enables the development of new interventions; it promotes the understanding of the interaction of the brain with the central nervous system and psychosocial elements, maximizing the effectiveness of the multidisciplinary communication process through the use of terminology shared by other clinical areas.

Therefore, according to Farmer (2009), the relationship established between neurosciences and social work relates essentially to the fact that it is a professional area which deals with psychosocial challenges encountered by individuals and families as well as social behaviors, therefore being inextricably linked to social neuroscience.

"The term "social neuroscience" was introduced in 1992 to describe a field of research - or set of fields - using social and biological levels of analysis (Cacioppo \& Bernston, 1992). It analyzes concepts and ideas from the neural to the social level (Ito \& Cacioppo, 2001)" (Farmer, 2009, p. 11).

The author points out that some areas of brain development are indispensable to understand the mechanisms and structure of brain activity as well as its development in the context of neuroscience and psychosocial development throughout life.

"Social workers have historically worked with persons who experience environmental deprivations as well as serious emotional and psychiatric problems, and social neuroscience is a resource for such work" (Farmer, 2009, p. 17).

Matto (2013) considers that advances in the knowledge of brain function enabled the understanding of transactional interdependencies between brain, behavior and environment, bringing new opportunities for social workers to transform their working methods as agents of social changes through the systems.

"The current decade of discovery is focused on advancing understanding of the ways in which strategic psychosocial interventions act on brain structures to change behavioral response. This focus is deeply relevant to the person-inenvironment perspective integral to the social work profession. In advancing our profession's practice models to incorporate current brain science research, social workers will be positioned to more effectively work with the diverse client populations and settings of our profession, and we can use such knowledge to inform advocacy efforts, influence human service policy decisions, and contribute to practitioner education" (Matto, 2013, p. 2).

Matto (2013) states that these contributions have several implications for education and practice. The author considers that, on the one hand, the biopsychosocial perspective of social work practice has been highlighted in many social work schools but, on the other hand, the biological components of this threefold perspective have not been developed enough. 
Johnson (2014) believes that the more we learn about neuroscience and its connections, the better we are equipped to assist the people we serve. The author raises relevant questions for social workers to think about:

-How do individual differences interact with environmental forces to mold our lives?

- How can we make connections between the conditions we encounter every day in our work, such as substance abuse, psychiatric challenges or family violence, and the invisible changes in our brains that lie behind these visible psychological events?

Following Farmer (2009), Blundo (2015) considers social neuroscience a tool which can help social work students to be better in the area of intervention, assisting them in developing critical thinking skills and social-emotional learning, in addition to increasing empathy towards their clients.

- Concepts and links to social work practice: some contributions

Researchers have developed many lines of thought and input in the field of social work. Therefore and in order to clarify some neuroscience concepts and their importance to social work, we present the following summary table (table 2):

\section{Table 2 - Neuroscience concepts and their importance to social work}

\begin{tabular}{|l|l|}
\hline Author/Year & Concepts \\
\hline Shapiro, J.R. (2010) & Neurobiology of attachment (affect regulation), memory \\
\hline $\begin{array}{l}\text { Egan, M., Combs-Orme, T. \& Neely- } \\
\text { Barnes, S.L. (2011) }\end{array}$ & $\begin{array}{l}\text { Sritical and sensitive periods of development, neural plasticity, cognitive aspects and memory, } \\
\text { Stress and trauma }\end{array}$ \\
\hline Montgomery, A. (2013) & $\begin{array}{l}\text { Autonomic nervous system (ANS) and the phenomena such as disorders of personality, defense } \\
\text { mechanisms and attachment styles; brain plasticity; dysregulation affect; the ego and the right } \\
\text { hemisphere }\end{array}$ \\
\hline Matto, H. (2013) & Mirror neurons, empathy \\
\hline Farmer, R.L. (2009) & $\begin{array}{l}\text { Mirror neurons, brain development of children and adolescents, trauma, feeling, remembering, } \\
\text { learning }\end{array}$ \\
\hline $\begin{array}{l}\text { Matto H., Strolin-Goltzman, } \\
\text { Ballan, M.S. (2014) }\end{array}$ & Empathy \\
\hline Miehls, D. (2014) & $\begin{array}{l}\text { Plasticity, right and left brain hemisphere, information processing and memory Potential of } \\
\text { reparative relationships }\end{array}$ \\
\hline $\begin{array}{l}\text { Combs-Orme, W., Cain, P. \& Kirby } \\
\text { (2003) }\end{array}$ & The importance of brain growth between the age group of 0-3 \\
\hline
\end{tabular}

Egan, Combs-Orme, \& Neely-Barnes (2011) introduce important concepts to social work, such as critical and sensitive periods of development, neural plasticity, cognitive aspects and memory, stress and trauma:

Critical and/or sensitive period - it refers to development stages during which a given brain structure or area is particularly receptive to external stimuli and quickly establishes a multitude of connections between the neurons and the vigilant system, each one interacting with other systems.

Neural plasticity - it means that the neurons and neuronal connections can grow and change throughout life, and also involve different psychosocial aspects, such as lifelong learning, the influence of the environment on how to process emotions and the influence of stress and trauma on the brain.

Cognition and memory - it is the ability to solve and store information and develop solutions to problems. The cognitive process occurs in the cerebral cortex.

Stress and trauma - the importance of stress and trauma to the ecological perspective already has a long tradition in social work; however, new findings in neuroscience unveiled the role of brain functions in adaptation and non-adaptation responses to stress and trauma for the person's future development.

In this line of analysis following the neurobiology perspective, Miehls (2011) also focuses on these brain areas and functions as being relevant to social work practice. 
Montgomery (2013) offers examples of shared concepts between successful psychodynamic interventions and neuroscience research, and of their integration into social work practice. The author describes the four major contributions made by neuroscientific findings to the clinical practice, pointing out that three of them incorporate thelink between the autonomic nervous system (ANS)andthephenomenon ofclinical interventions such as personality disorders, defense mechanisms and styles of attachment. This last point relates to the connection between the ego functions and the activity of the right side of the brain. The author states that special attention has been given to the field of affect dysregulation because it is considered a main risk factor in a variety of psychosocial difficulties.

Farmer (2014) describes and addresses the implications regarding the relevance of mirror neurons to social work practice. The author refers that "mirror neurons" have important implications for social work theorizing and practice. "Thought research on these specialized visuomotor neurons is still in its early stages, the mirror system (MNS) links visual and motor experiences; makes possible implicit learning via imitation of what is seen, heard, and felt; and is believed to be involved in the development of empathy and understanding the intentions of others" (Idem, 2014, p.37).

The author mentions that by integrating these concepts into social work practice, it is possible to deepen our knowledge about behavior and its importance to communication, and the ways of applying such understanding to the design of social interventions; our understanding of the therapeutic relationship between client and practitioner; and the link between the theory of attachment, the social brain and its development. Much of the endeavors undertaken by social work take place in the context of relationships established between social workers and clients, at the core of the aid relationship.

Sayre (2014) explores the connection between the theory of evolution and neuroscience, considering that the combination of the two can enrich the theoretical foundation of social work and provide not only coherence to the way social workers understand the complexity of the world but also guidance for enhanced interventions. The author states that neuroscience is based on Darwin's theory of evolution (Cozolino, 2010; Farmer, 2009) which can provide a different theoretical component to steer the social work practice. "In evolutionary theory, the ultimate function of any adaptation is to increase the chances of gene survival" (cit. in Sayre, 2014, p. 970).

Several authors provide examples of application of neuroscience to social work:

Shapiro and Applegate (2000) discuss the clinical applications of new information about the impact of care provision on early child brain development.

Matto and Strolin-Goltzman (2010) defend the incorporation of social neuroscience into social work assessments and practice development.

Gerdes, Lietz and Segal (2011) address the connections between neuroscientific research on mirror neurons and the measurement of empathy in order to improve client assessment in social work.

Gerdes, Segal, Jackson and Mullins (2011, p. 968), "presented a method of engaging students' mirror neurons for the purpose of improving effective development of empathy: 'Affect-basedexperiential learning engages mirror neurons at the visual, auditory, and somatic levels, helping us to relate to experiences we may never have had, thereby increasing empathy"'.

Egan, Combs-Orme and Neely-Barnes (2011, p. 968) "outlined themes from neuroscience research that can be included in courses in human behavior and the social environment, astutely noting ties to social policy advocacy".

Reyes (2016) also stresses that this knowledge is of the utmost importance to social work practice. The author believes that its findings allow us to understand social, behavioral and human problems and their consequences to individual and social well-being, while also providing a new perspective based on which these problems can be analyzed and addressed, particularly in relation to empathy,mental health, attachment, addictions, neurodegenerative diseases, stress and posttraumatic situations.

According to Matto and Strolin-Goltzman (2010), there are significant links between high-stress environments, such as extremely poor milieus, exposure to chronic violence, scarcity of opportunities and consumption experiences,and the psychobiological imbalance or theincrease ofthe allostatic load (McEwen, 2001), due to the excess or ineffectiveness of the adaptation processes used by people in order to maintain the organism stable (McEwen, 2001). 


\section{Concluding remarks}

Common to all researchers is the emphasis on the need to continually incorporate the neuroscientific perspective into social service as far as training, practice and research are concerned.

"Indeed, from a social justice perspective, social workers have a unique obligation to participate in and contribute to neuroscientific research" (Matto, 2010, p.150).

"Social work has long advocated a biopsychosocial perspective in understanding and treating individual and social problems. (...) Despite an emphasis on a biopsychosocial understanding of human behavior and the relevance of biosocial research to social work practice, it is unclear whether social work is contributing to biosocial research and knowledge."(Maynard, Boutwell, \& Vaughn, 2015, p. 1) "

As stated by Miehls (2014), we must always bear in mind that neuroscience findings are constantly increasing and rapidly evolving, making it imperative to be acquainted with them.

This literature review permitted the identification of approaches andtheoretical observations on the relationship between social work and neuroscience which underline its importance not only to the training given to social workers but also to their professional practice. However, the research is still limited and therefore the development of new studies in emerging fields is encouraged. Given its expertise and experience in dealing with social problems and promoting human well-being, social work can give an important contribution.

"Despite developments in these lines of research, science has only begun to examine the effects of psychosocial interventions on brain structure and function. More research must be conducted in this emerging field, and the social work profession, with its expertise in addressing social problems and enhancing human well-being, can make a vital contribution to this endeavor" (Garland et al., 2009, p. 8).

As stated by Johnson (2014): "Neuroscience is still a long way from having all the answers. In fact, it's only recently made its entrance. But it offers explanations that can help you answer some of these questions better than you could without it."

It is important to mention the existence of different theoretical and practical guidelines that shape social intervention in social work training and practice at an international level. Not all countries have incorporated the area of clinical social service into their courses, so the contribution of these findings to education begins right here with this question.

\section{References}

[1] Blundo, R. (2015). Neuroscience and Future Social Work Curriculums. The New Social Worker Magazine. Retrieved from: http://www.socialworker.com/feature-articles/practice/neuroscience-and-future-social- workcurriculums/ Accessed June 1, 2018.

[2] Cacioppo, J.T., Visser, P.S., \& Pickett, C.L. (2006). Social neuroscience: People thinking about thinking people. Cambridge, MA: MIT Press.

[3] Combs-Orme, W., Cain, P. \& Kirby (2003). Early Brain Development for Social Work Practice: Integrating Neuroscience with Piaget's Theory of Cognitive Development. Journal of Human Behavior in the Social Environment, 23, 640-647.

[4] Cozolino, L. (2010). The Neuroscience of Psychotherapy: Healing the Social Brain (2 ${ }^{\text {nd }}$ ed.). New York: W.W.Norton \& Co.

[5] DiPietro, J.A. (2000). Baby and the brain: Advances in child development. Annual Review of Public Health, 21, 455-471.

[6] Dziegielewski, S. (2010). Social Work Practice Psychopharmacology - A Person-in-Environment Approach (2 ${ }^{\text {nd }}$ ed.). Springer: Publishing Company.

[7] Egan, M., Combs-Orme, T., \& Neely-Barnes, S.L. (2011). Integrating neuroscience knowledge into social work education: A case-based approach. Journal of Social Work Education, 47(2), 269-282.

[8] Farmer, R.L. (2009) Neuroscience and Social Work Practice: The Missing Link. Thousand Oaks, California: SAGE.

[9] Farmer,R.L.,(2014).MirrorNeurons.In.Matto,H.C.,Strolin-Goltzman,J.,Ballan,M.S.(Coord.) 
[10] Neuroscience for Social Work. Current Research and Practice (Chap. 3, p.37). New York: Springer.

[11] Garland, EL., \& Mo, H. Neuroplasticity, Psychosocial Genomics, and the Biopsychosocial Paradigm in the $21^{\text {st }}$ Century. Health Social Work, 34(3), 191-199.

[12] Gerdes, K. E., Lietz, C.A., \& Segal, E.A. (2011). Measuring empathy in the $21{ }^{\text {st }}$ century: Development of an empathy index rooted in social cognitive. Journal of Social Work Research, 35(2), 83-93.

[13] Gerdes, K. E., Lietz, C.A., Segal, E.A., Jackson, K.F., \& Mullins, J.L. (2011). Teaching empathy: A framework rooted in social cognitive neuroscience and social justice. Journal of Social Work Research, 47(1), 109-131.

[14] Ito, T.A., \& Cacioppo, J.T. (2001). Affect and attitudes: A social neuroscience approach. In J.P. Foyas (Ed.), Handbook of affect and social cognition (50-74). Mahwah, NJ: Lawrence Erlbaum.

[15] Johnson, H. (2014). Behavioral Neuroscience for the Human Services: Foundations in Emotion, Mental Health, Addiction, and Alternative Therapies. Oxford, UK: Oxford University Press.

[16] Manes, F. (2014). Usar el cerebro (4⿳a ed). Ciudad Autónoma de Buenos Aires: Planeta.

[17] Matto, H., \& Strolin-Golzman, J. (2010). Integrating Social Neuroscience and Social Work: Innovations for Advancing Practice-Based Research. Social work, April, 55(2), 147-56.

[18] Matto, H.C., Strolin-Goltzman, J., Ballan, M.S. (2014). Neuroscience for Social Work. Current Research and Practice. New York: Springer.

[19] Maynard, B., Boutwell, B., \& Vaughn, M. (2015). Biosocial Research in Social Work Journals: A Systematic Review. Research on Social Work Practice, 1-9.

[20] McCutcheon, V.V. (2006). Toward an integration of social and biological research. Social Service Review, 80, $159-178$.

[21] McEwen, B.S., (2001). Plasticity of the hippocampus: adaptation to chronic stress and allostatic load.

[22] Annals of the New York Academy of Sciences, Vol 933, 265-77.

[23] Montgomery, A. (2013). Toward the integration of neuroscience and clinical social work. Journal of Social Work Practice, 27(3), 333-339.

[24] National Association of Social Workers (2003). NASW standards for integrating genetics into social work practice. Washington, DC: Press Author Center.

[25] Negash, S., \& Petersen, R. (2006). Societal influences that affect cognitive functioning in old age. In K. Warner Schaie \& L.L. Cartensen (Eds.), Social structures, aging, and self-regulation in the elderly (1-31). New York: Springer.

[26] Reyes, M. (2016). El impacto de los avances neurocientíficos en la profesión del Trabajo Social: presente y propuestas de futuro. Documentos de Trabajo Social, 57. ISSN 1133-6552 / e-ISSN 2173-8246. Retrieved from: https://dialnet.unirioja.es/descarga/articulo/6095377.pdf

[27] Rutledge, N. (2014). Neuroscience and Social Work. Toward a Brain Based Practice. Social Work Today, June, 14(3), 22.

[28] Sayre, M., \& Walker, R. (2014). Evolutionary Theory and Neuroscience: An explanatory Theory for Social Work. Journal of Human Behavior in the Social Environment, 24(8), 966-972.

[29] Sena, A. (2016). Cérebro, Saúde e Sociedade. Lisboa: Lidel - Edições Técnicas Lda.

[30] Shapiro, J.R., \& Applegate, J.S. (2005). Neurobiology for Clinical Social Work. Theory and Practice. New York: W.W. Norton \& Co.

[31] Wax, A.(2017). The Poverty of the Neuroscience of Poverty: Policy Payoff or False Promise?. Faculty Scholarship. 1711. Retrieved from: https://scholarship.law.upenn.edu/faculty_scholarship/1711/

[32] Weatherston, D. (2001). Infant mental health: A review of relevant literature. Psychoanalytic Social Work, $8(1), 39-69$. 